www.jmscr.igmpublication.org

Index Copernicus Value: 79.54

ISSN (e)-2347-176x ISSN (p) 2455-0450

crossrefDOI: https://dx.doi.org/10.18535/jmscr/v7i1.119

\title{
Lobular Capillary Hemangioma of Nasal Cavity-A Rarity
}

\author{
Author \\ Dr Prashant Nanwani \\ ${ }^{1}$ Senior Resident, Department of E.N.T., Pt. J.N.M. Medical College, Raipur \\ Corresponding Author \\ Dr Prashant Nanwani \\ S/O-Sukhdev Nanwani, Station Road Naharpara, Behind Sindhi Dharamshala, Raipur, \\ Chhattisgarh-492009, India \\ Email: nanwaniprashant@gmail.com, Mob.No.9827881201/6264847575
}

\section{Introduction}

Nasal lobular capillary hemangioma $(\mathrm{LCH})$ is a benign lesion, exact etiology of which is not known and it is commonly associated with pregnancy, oral contraceptives and trauma. Nasal obstruction and epistaxis are the symptoms which are commonly found in patients of nasal lobular capillary hemangioma. Skin and mucous membrane are the common location for lobular capillary hemagioma and it is usually solitary. The occurrence of lobular capillary hemangioma is rare in the nasal cavity ${ }^{[2]}$.

Hormonal factors and trauma are supposed to be the common factors ${ }^{[2]}$. We present a case of lobular capillary hemangioma, which was located in the anterosuperior part of nasal septum on left side. We recommend to consider this rare entity in differential diagnosis of bleeding nasal mass.

\section{Case Report}

A 47 year old male patient presented with chief complaint of recurrent bleeding from left nasal cavity since one month. The patient was a known case of migraine for which he was not taking any medication. There was no history of trauma, nasal obstruction, nasal discharge, hypertension. He was the labour by profession.

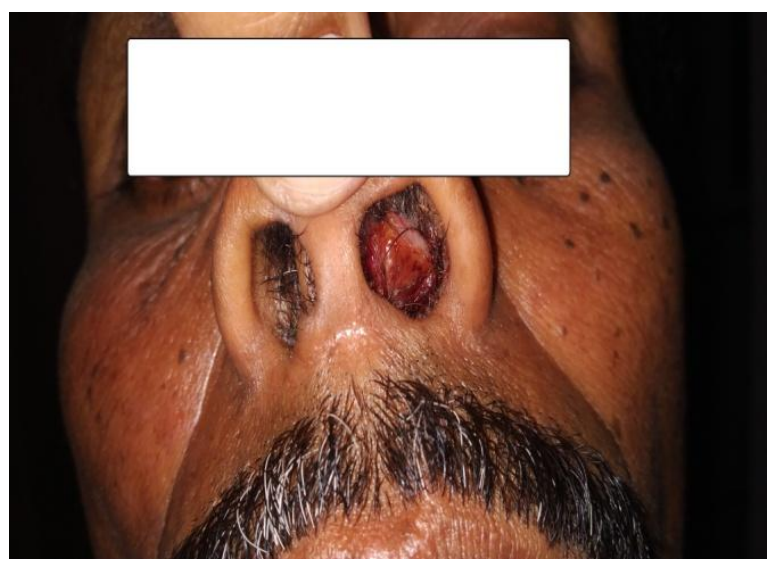

\section{Endoscopy}

A reddish mass with blood clots over it was seen attached to anterosuperior part of nasal septum on left side. Rest there was no any deformity seen. 


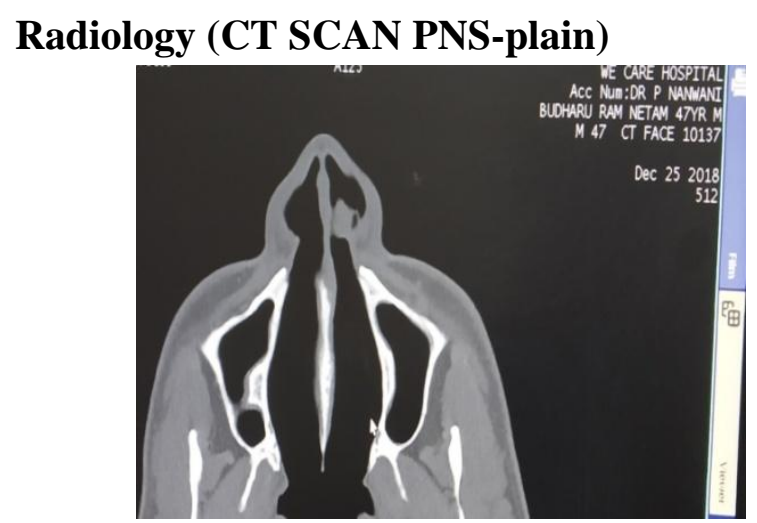

A polypoidal soft tissue density lesion was seen over anterior part of nasal septum on left side.

\section{Excised Specimen}

Excision of the nasal mass was done with cauterization of base. There was no bleeding during the procedure and soft tissue was sent for histopathological examination.

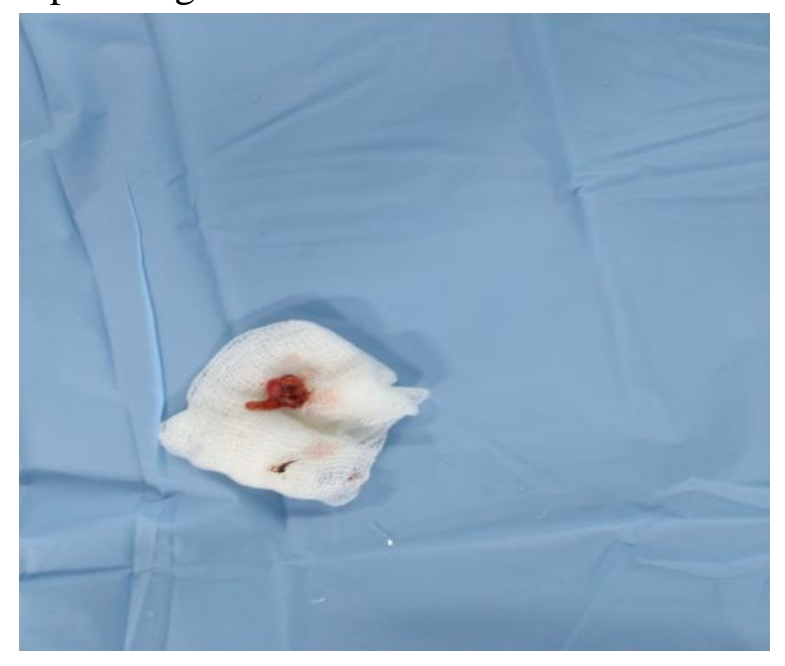

\section{Histopathological Examination}

GROSS - received a reddish soft tissue bit mixed with mucus together measuring $0.6 \times 0.4 \times 0.3 \mathrm{~cm}$. Cut surface is grey brown, soft.

Microscopy- An exophytic lesion with acanthotic collarette and surface ulceration and a stromal bening lobular capillary proliferation.

Impression-Suggestive of lobular capillary hemangioma (Pyogenic Granuloma)

\section{Discussion}

Lobular capillary hemangioma (LCH), previously called pyogenic granuloma, are benign polypoid forms of capillary hemangioma which occur primarily on skin and mucous membranes. Lobular capillary hemangioma mostly seen in third decade though it can occur in all ages and is more common in females. Males are affected more in pediatric age group $^{[3]}$. Mucosal lobular capillary hemangioma commonly occur in gingival, lips, tongue and buccal mucosa, but involvement of nasal cavity is a rarity.

The exact cause of development of lobular capillary hemangioma is not know. The following factors like hormonal influence, trauma, viral oncogens, microscopic AV malformation have been suggested which might play a role in formation of lobular capillary hemangioma. Cases with post operative nasal pack have been associated with lobular capillary hemangioma ${ }^{[2,4]}$.

The most common symptoms are nasal obstruction and epistaxis ${ }^{[2,4]}$. It can be pedunculated or wide based. Its size ranges from several millimetres to centimetres. Littles's area is the usual location in nasal cavity. Involvement of middle turbinate has been seen in cases of nasal packing $^{[5]}$. Imaging of lobular capillary hemangioma is done by contrast enhanced CT scan of paranasal sinuses where scan generally reveals soft tissue mass with or without associated bony destruction.

The submucosal vascular proliferation arranged in lobules is the prominent finding in histopathological examination. There is no intercommunication of vascular spaces or cytological atypia ${ }^{[6]}$. When we consider the differential diagnosis we should include rhinosporodiosis which is a vascular mass having tiny white dots over it imparting strawberry like appearance, cavernous hemangioma whose occurance in nasal cavity is less frequent and nasopharyngeal angiofibroma in adolescent male ${ }^{[7]}$.

The treatment of choice is complete surgical excision. When the lesion is large, the differentiation from other hyper vascularised lesions may be intriguing. The preferred treatment choice is endoscope through which diagnosis and surgery can be easily done. This case is reported 
for its potential for being misdiagnosed and to highlight the advantage of nasal endoscopes in diagnosis and treatment

\section{Conclusion}

Lobular capillary hemangioma is a rare entity of unknown etiology especially in nasal cavity. Though a rarity whenever we consider the differential diagnosis of vascular mass in nasal cavity it should always be included. Endoscopic guided excision is the treatment of choice.

Conflicts of Interest: None identified

\section{References}

1. Puxeddu R, Berlucchi M, Ledda GP, Parodo G, Farina D, Nicolai P. Lobular capillary hemangioma of the nasal cavity: A retrospective study on 40 patients. Am J Rhinol. 2006;20:480-484. [PubMed].

2. C. Ozcan, D.D. Apa, K. Görür Pediatric lobular capillary hemangioma of the nasal cavity Eur Arch Otorhinolaryngol, 261 (2004), pp. 449-451

3. Ozcan C, Apa DD, Gorur K. Pediatric lobular capillary hemangioma of the nasal cavity. Eur Arch Otorhinolaryngol 2004;261:449-451. [PubMed]

4. Kapella M, Panosetti E, Rombaux P, Delos M, Weynand B. Lobular capillary haemangioma of the nasal cavity: observation of three specific cases. Acta Otorhinolaryngol Belg. 2001;55:241246. [PubMed]

5. Kurtaran H, Uraldi C, Ark N, Aktas D. Lobular capillary haemangioma of the middle turbinate. Acta Otolaryngol. 2006;126:442-444. [PubMed].

6. El-Sayed Y, al-Serhani A. Lobular capillary haemangioma (pyogenic granuloma) of the nose. J Laryngol Otol. 1997;111:941-945. [PubMed]

7. Katori H, Tsukuda M. Lobular capillary hemangioma of the nasal cavity in child. Auris Nasus Larynx. 2005;32:185188. [PubMed] Epub. 2005;23 [PubMed] 